\title{
Using CFD To Assess The Impact of Helical Baffle On The First- Law And Second-Law Performance of Water-CuO Nanofluid Inside A Hairpin Heat Exchanger
}

\author{
Amin Shahsavar \\ Kermanshah University of Technology \\ Davood Toghraie ( $\sim$ Toghraee@iaukhsh.ac.ir) \\ Islamic Azad University \\ Pouya Barnoon \\ Islamic Azad University
}

\section{Research Article}

Keywords: Numerical simulation, Heat exchanger, Turbulator, Nanofluid, Irreversibility

Posted Date: September 8th, 2021

DOI: https://doi.org/10.21203/rs.3.rs-877881/v1

License: (c) (i) This work is licensed under a Creative Commons Attribution 4.0 International License.

Read Full License 


\title{
1 Using CFD to assess the impact of helical baffle on the first-

Amin Shahsavar ${ }^{1}$, Davood Toghraie*2, Pouya Barnoon ${ }^{2}$

Keywords: Numerical simulation; Heat exchanger; Turbulator; Nanofluid; Irreversibility.

*Corresponding author Email: Toghraee@iaukhsh.ac.ir

\begin{abstract}
This study is devoted to the numerical assessment of the influence of helical baffle on the hydrothermal aspects and irreversibility behavior of the turbulent forced convection flow of water-CuO nanofluid (NF) inside a hairpin heat exchanger. The variations of the first-law and second-law performance metrics are investigated in terms of Reynolds number (Re), volume concentration of NF ( $\varphi$ ) and baffle pitch (B). The results showed that the NF Nusselt number grows the rise of both the Re and $\varphi$ whereas it declines by boosting with the rise of baffle pitch. In addition, the outcomes depicted that the rise of both the $R e$ and $\varphi$ results in the rise of pressure drop, while it declines with the increase of baffle pitch. Moreover, it was found that the best first-law performance of the NF belongs to the case $B=33.3 \mathrm{~mm}, \varphi=2 \%$ and $\mathrm{Re}_{\mathrm{nf}}=10000$. Furthermore, it was shown that irreversibilities due to fluid friction and heat transfer augment with the rise of $\mathrm{Re}$ while the rise of baffle pitch results in the decrease of frictional irreversibilities. Finally, the outcomes revealed that with the rise of baffle pitch, the heat transfer irreversibilities first intensifies and then diminishes.
\end{abstract}


33 It is well known that the turbulent flow has a higher heat exchange and pumping power than the

34 laminar flow, the former being desirable and the latter undesirable. So, the idea came into the 35 researchers' minds to put equipment in the path of laminar flow and create local turbulence. The 36 idea was very successful and has been widely used in the industry today. This equipment is 37 called turbulator, and so far, various types of turbulators have been introduced and their 38 performance has been studied experimentally and numerically [1-10]. Although the use of turbulators has led to an improvement in the performance of heat transfer 40 systems, this has not prevented researchers from looking for ways to further improve the 41 performance of these systems. One of these amazing techniques, which originated from the low 42 thermal conductivity of heat transfer fluids, is nanofluid (NF). Choi [11] first made these modern 43 fluids and called them NFs. After the introduction of NFs and their amazing thermal properties, 44 much research has been done on their performance in diverse applications [12-15].

45 The literature inspection shows that the performance of thermal systems with NF coolants 46 equipped with turbulators has been investigated by various researchers. Bellos et al. [16] 47 analyzed the efficacy of oil-CuO NF in a parabolic trough collector equipped with turbulators. 48 They found that using the combination of NF and turbulator causes a $1.54 \%$ thermal efficiency 49 improvement. Nakhchi and Esfahani [17] inspected the efficacy of aqueous $\mathrm{Cu} \mathrm{NF}$ inside a 50 heated tube equipped with perforated conical rings in a turbulent regime. It was reported that 51 using compound NF and turbulator results in a considerable heat transfer intensification. 52 Akyurek et 1. [18] experimentally evaluated the forced convection flow of water- $\mathrm{Al}_{2} \mathrm{O}_{3} \mathrm{NF}$ inside 53 a horizontal tube equipped with wire coil turbulator. They utilized two turbulators with different 54 pitches and found that the performance metrics of tube filled with NF without any turbulator is 
55 superior to that of the cases with turbulator. Xiong et al. [19] simulated the efficacy of aqueous

$56 \mathrm{CuO}$ NF flowing inside a tube having a compound turbulator. The outcomes portrayed that using

57 turbulator elevates the rate of heat exchange between tube wall and NF. Xiong et al. [20]

58 numerically investigated the forced convection of NF through a pipe equipped with a complex-

59 shaped turbulator. They inspected the consequence of elevating width ratio, flow rate and pitch

60 ratio on the performance features. It was found that the Nusselt number intensifies with boosting

61 pitch ratio of turbulator. In a numerical investigation, Ahmed et al. [21] explored the forced

62 convection of water- $\mathrm{Al}_{2} \mathrm{O}_{3}$ and water-CuO NFs inside a triangular duct with a delta-winglet pair

63 of turbulator under turbulent flow regime. They reported the significant effect of using both NF

64 and turbulator on the performance aspects.

65 The design of a heat transfer system can be done both according to the first-law or the second-

66 law of thermodynamics. If the first-law applies, the system must have the highest overall

67 hydrothermal performance, and if the second-law applies, the system performance must have the

68 least irreversibility. The efficacy of NF flow in turbulator-equipped thermal units has rarely been

69 investigated from a second-law perspective [22-25]. Sheikholeslami et al. [22] inspected the

70 irreversibility features of turbulent flow of aqueous $\mathrm{CuO} \mathrm{NF}$ inside a pipe equipped with

71 complex turbulators. Li et al. [23] simulated the NF irreversibility in a tube with helical twisted

72 tapes. The thermal irreversibility was found to be declined with elevating the height ratio of

73 turbulator, while the opposite is true for the frictional irreversibility. Farshad and Sheikholeslami

74 [24] analyzed the irreversibility aspects for aqueous $\mathrm{Al}_{2} \mathrm{O}_{3} \mathrm{NF}$ flow in a solar collector having a

75 twisted tape. The outcomes revealed that the irreversibility diminishes with the increase of

76 diameter ratio. Al-Rashed et al. [25] examined the influence of nanomaterials type on the 
77 irreversibility production of a $\mathrm{NF}$ in a heat exchanger. It was reported that the maximum

78 irreversibility belongs to the platelet shape nanomaterials.

79 The aim of this numerical work is to evaluate the features of turbulent flow of a NF through a

80 hairpin heat exchanger equipped with helical baffles in the annulus side from both the fist and

81 second-law perspectives. The impacts of baffle pitch, $R e$ and $\varphi$ on the NF efficacy are assessed.

82 This investigation is the first work on the consequences of using helical baffle on the 83 irreversibility production inside an annulus of a hairpin heat exchanger filled with NF.

84

\section{2. Problem statement}

86 Fig. 1 gives a demonstrative sketch of geometry under investigation. It is a hairpin heat

87 exchanger with $100 \mathrm{~mm}$ length, $10 \mathrm{~mm}$ inner tube internal diameter, and $15 \mathrm{~mm}$ outer diameter

88 internal diameter. Additionally, the wall thickness for both the inner and outer tubes is $1 \mathrm{~mm}$.

89 Moreover, the baffle pitch varies from $25 \mathrm{~mm}$ to $100 \mathrm{~mm}$.

90 The purpose of using this device is to cool the NF passing through the annulus with the help of 91 water passing through the inner tube. In both water and nanofluid streams, time is of the essence 92 and both streams are in turbulent regime. Both streams enter the device at a uniform velocity and 93 temperature and are discharged into the atmosphere. Also, the exterior wall of heat exchanger is 94 considered as insulated and no slip condition is utilized on the walls. 
96

97

98

99

100

101

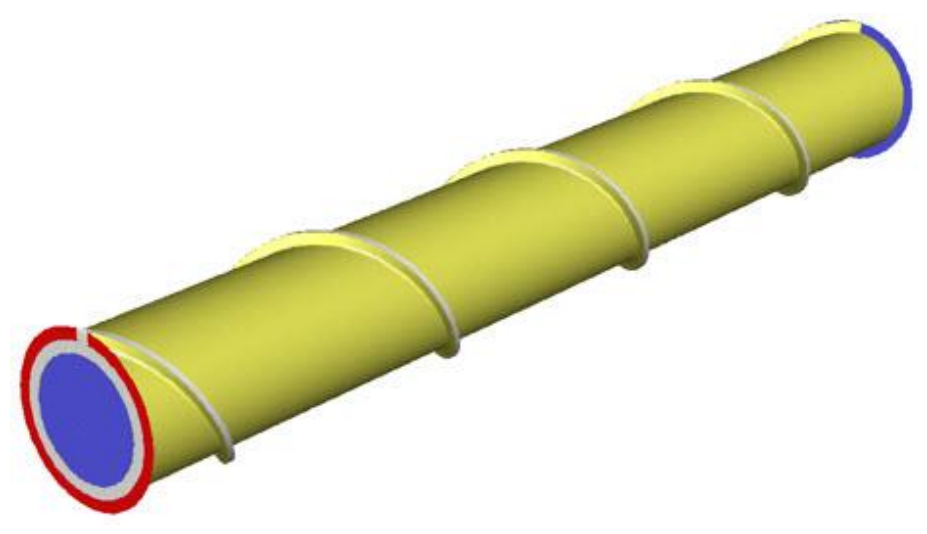

(a) $B=25 \mathrm{~mm}$

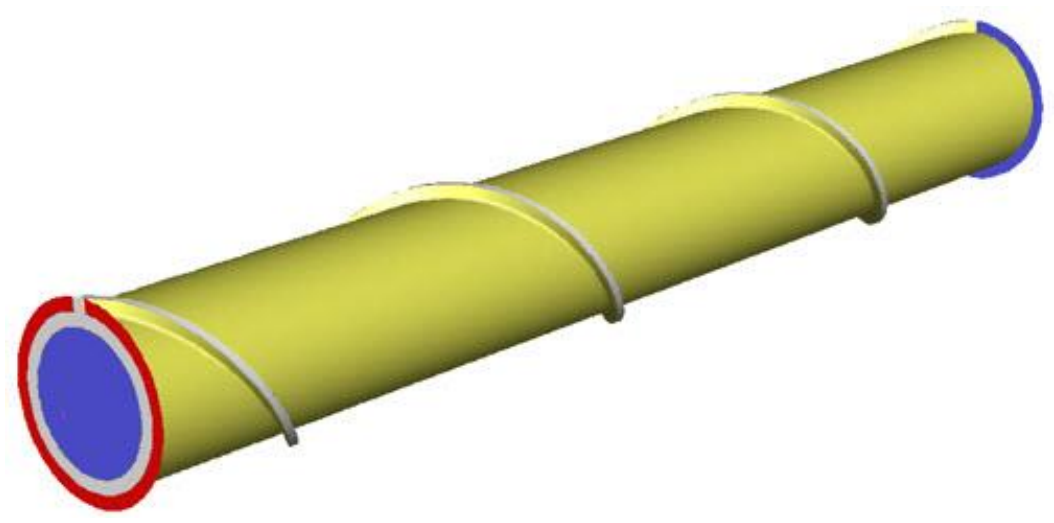

(b) $B=33 \mathrm{~mm}$

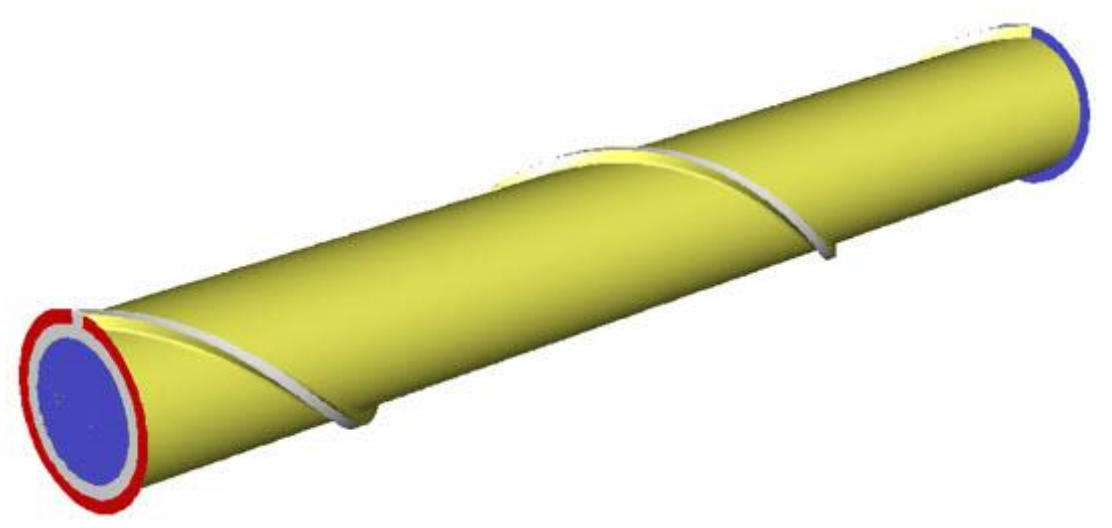

(c) $B=50 \mathrm{~mm}$ 
102<smiles>[C]C(C)C</smiles>

104

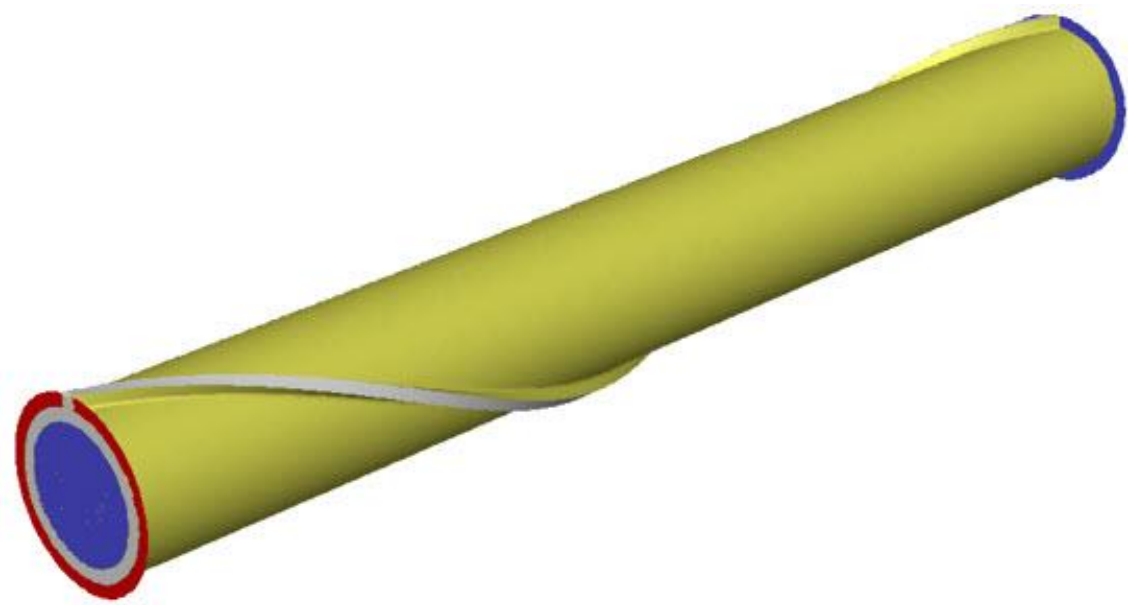

(d) $B=100 \mathrm{~mm}$

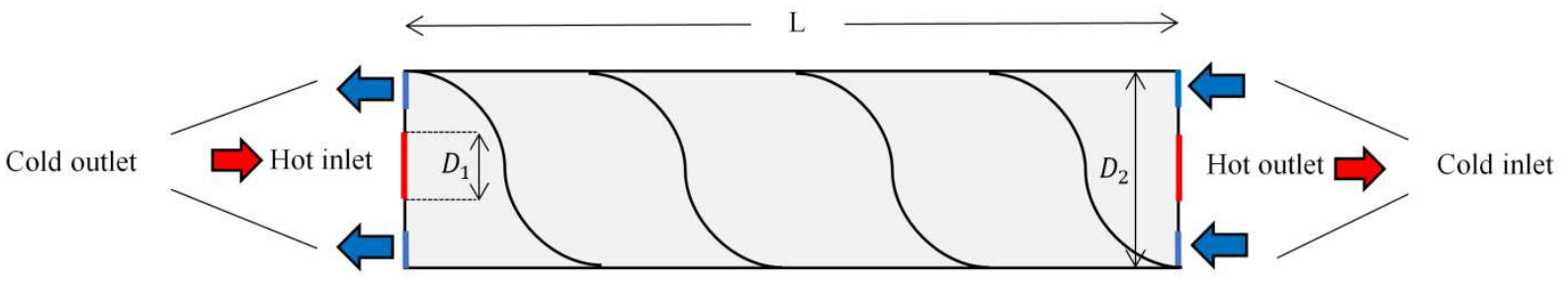

(e) 2-D view

Fig. 1. Schematic sketch of the problem.

107

\section{Governing equations and problem parameters}

109

Continuity equation

$110 \quad \frac{\partial\left(u_{i}\right)}{\partial x_{i}}=0$

\section{Momentum equation}

$112 \frac{\partial}{\partial x_{j}}\left(u_{j} \rho_{n f} u_{i}\right)=-\frac{\partial p}{\partial x_{i}}+\frac{\partial}{\partial x_{j}}\left[\mu_{n f}\left(\frac{\partial u_{i}}{\partial x_{j}}+\frac{\partial u_{j}}{\partial x_{i}}\right)\right]+\frac{\partial}{\partial x_{j}}\left(-\rho_{n f} \overline{u_{j}^{\prime} u_{l}^{\prime}}\right)$

\section{Energy equation}

$114 \frac{\partial}{\partial x_{i}}\left(\rho_{n f} T u_{i}\right)=\frac{\partial}{\partial x_{i}}\left[\left(\mu_{t} / P r_{t}+\mu_{n f} / P r_{n f}\right) \frac{\partial T}{\partial x_{i}}\right]$ 
115 where $\mu_{t}$ and $\rho_{n f} \overline{u_{\jmath}^{\prime} u_{\imath}^{\prime}}$ are defines as follows;

$116 \mu_{t}=\rho_{n f} C_{\mu} k^{2} / \varepsilon$

$117 \mu_{t}\left(\frac{\partial u_{i}}{\partial x_{j}}+\frac{\partial u_{j}}{\partial x_{i}}\right)-\frac{2}{3} \delta_{i j}\left(\rho_{n f} k+\mu_{t} \frac{\partial u_{k}}{\partial x_{k}}\right)=-\rho_{n f} \overline{u_{j}^{\prime} u_{\imath}^{\prime}}$

$118 k \& \varepsilon$ parameters are defined as follows;

$119 \frac{\partial}{\partial x_{j}}\left[\frac{\partial k}{\partial x_{j}}\left(\mu_{n f}+\frac{\mu_{t}}{\sigma_{k}}\right)\right]-\rho_{n f} \varepsilon+G_{k}=\frac{\partial}{\partial x_{i}}\left(u_{i} \rho_{n f} k\right)$

120 where

$121 \quad G_{k}=-\frac{\partial u_{j}}{\partial x_{i}} \rho_{n f} \overline{u_{\jmath}^{\prime} u_{\imath}^{\prime}}$

$122 \frac{\partial}{\partial x_{i}}\left(\rho_{n f} u_{i} \varepsilon\right)=\frac{\partial}{\partial x_{j}}\left[\frac{\partial \varepsilon}{\partial x_{j}}\left(\mu_{n f}+\frac{\mu_{t}}{\sigma_{\varepsilon}}\right)\right]+\frac{\varepsilon}{k} G_{k} C_{1 \varepsilon}-\rho_{n f} \frac{\varepsilon^{2}}{k} C_{2 \varepsilon}$

123 where

124

$P r_{t}=0.85 ; C_{\mu}=0.0845 ; \sigma_{k}=1 ; \sigma_{\varepsilon}=1.3 ; C_{1 \varepsilon}=1.42 ; C_{2 \varepsilon}=1.68$

The irreversible generation in forced convection flow of NF flow is due to two sources, namely fluid friction and heat exchange. Therefore, the total irreversibility is computed as:

$$
\begin{gathered}
S_{g e n}=\underbrace{\frac{\mu_{n f}}{T_{0}}\left\{2\left[\left(\frac{\partial u}{\partial x}\right)^{2}+\left(\frac{\partial v}{\partial y}\right)^{2}+\left(\frac{\partial w}{\partial z}\right)^{2}\right]+\left(\frac{\partial u}{\partial y}+\frac{\partial v}{\partial x}\right)^{2}+\left(\frac{\partial u}{\partial z}+\frac{\partial w}{\partial x}\right)^{2}+\left(\frac{\partial w}{\partial y}+\frac{\partial v}{\partial z}\right)^{2}\right\}}_{S_{g e n, f}} \\
+\underbrace{\frac{k_{n f}}{T_{0}^{2}}+\left[\left(\frac{\partial T}{\partial x}\right)^{2}+\left(\frac{\partial T}{\partial y}\right)^{2}+\left(\frac{\partial T}{\partial z}\right)^{2}\right]}_{S_{g e n, t}}
\end{gathered}
$$

By integrating the whole computational domain, the total irreversibility can be obtained: 
$131 S_{\text {tot }}=\int S_{g e n} d v$

132 Bejan number:

$133 B e=\frac{S_{g e n, t}}{S_{t o t}}$

134 The characteristic of a NF includes its thermo-physical properties that establish the relationship

135 between the base fluid and the nanoparticles. These basic relationships are defined as follows

136 [28-33]:

$137 \rho_{m}=\rho_{f}(1-\varphi)+\rho_{p} \varphi$

$138 \quad\left(\rho C_{p}\right)_{m}=\left(\rho C_{p}\right)_{f}(1-\varphi)+\left(\rho C_{p}\right)_{p} \varphi$

$139 \quad k_{n f}=k_{f} \frac{k_{p}+2 k_{f}+2 \varphi\left(k_{p}-k_{f}\right)}{k_{p}+2 k_{f}-\varphi\left(k_{p}-k_{f}\right)}$

$140 \quad \mu_{n f}=\left(123 \varphi^{2}+7.3 \varphi+1\right) \mu_{b f}$

141 The heat transfer rates for hot and cold fluids are calculated as follows:

$142 q_{h}=\dot{m}_{h} C_{p, h}\left(T_{h, i}-T_{h, o}\right)$

$143 \quad q_{c}=\dot{m}_{c} C_{p, c}\left(T_{c, i}-T_{c, o}\right)$

144 Average Nusselt number:

$145 \quad N u=\frac{h D_{h}}{k_{f}}$

146 The heat transfer coefficient [34-35]:

$147 \quad h=\frac{q^{\prime \prime}}{\Delta T_{L M T D}}$

148 where:

$149 \Delta T_{L M T D}=\frac{\Delta T_{2}-\Delta T_{1}}{\ln \left(\Delta T_{2} / \Delta T_{1}\right)}$ 
150 where;

$151 \Delta T_{2}=T_{h, o}-T_{c, i}$

$152 \Delta T_{1}=T_{h, i}-T_{c, o}$

$153 q^{\prime \prime}$ is the total heat flux that the fluid receives over the entire computational domain and is 154 calculated as $[28,29]:$

$155 \quad q^{\prime \prime}=\frac{1}{A} \int q^{\prime \prime}(x) d x$

156 The pressure drop $(\Delta P)$ is defined as follows:

$157 \Delta P=f \frac{L}{D_{h}} \frac{\rho u^{2}}{2}$

158 Thermal performance can be computed as:

$159 \eta=\frac{q}{\Delta P}$

\section{Numerical scheme, validation and Grid independency}

162 In the current numerical investigation, the simulations are conducted using the ANSYS Fluent

16318.1 software. The governing equations are discretized using the second-order upwind technique.

164 Besides, the SIMPLE scheme is utilized to perform the pressure-velocity coupling. The 165 convergence metric is set to $10^{-6}$.

166 Four different types of grids are used to make the outputs of the problem independent of the

167 mesh. Tetrahedral mesh is used. The walls have a boundary layer mesh with a factor of 5\%. The

168 Nusselt number is used to perform the mesh study. Finally, it was found that the most 169 appropriate mesh is the one with 650538 element number.

170 To ensure the accuracy and validity of the results of present work, the experimental findings of

171 Wen and Ding [37] and the numerical outcomes of Goktepe et al. [38] for the local convection 172 coefficient of NF flowing through a uniformly heated tube are employed. The outcomes are 
173 reported in Fig. 2. As can be observed, there is a good consistency between the outcomes and the

174 largest discrepancy between our results and the data from the other works (i.e. Refs. [37, 38]) is

$17510 \%$.

176 To further validate the simulations, the average Nusselt number of NF flow inside a channel with

177 rectangular rib (in-line) reported by Vanaki and Mohammed [39] is compared with our results.

178 As can be seen in Fig. 3, at low velocities, a good consistency is observed, and as the flow 179 velocity elevates, the discrepancy of the results is elevated and reaches to $7 \%$.

180

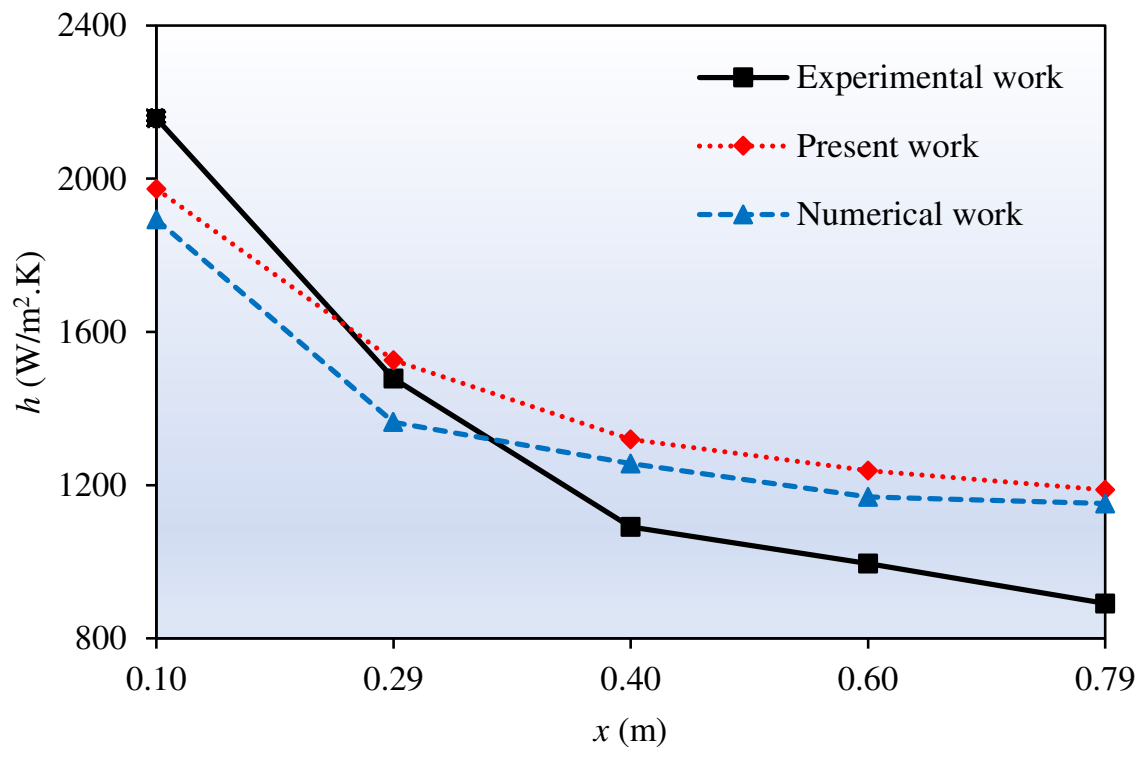

Fig. 2. Validation with experimental [37] and numerical [38] works. 


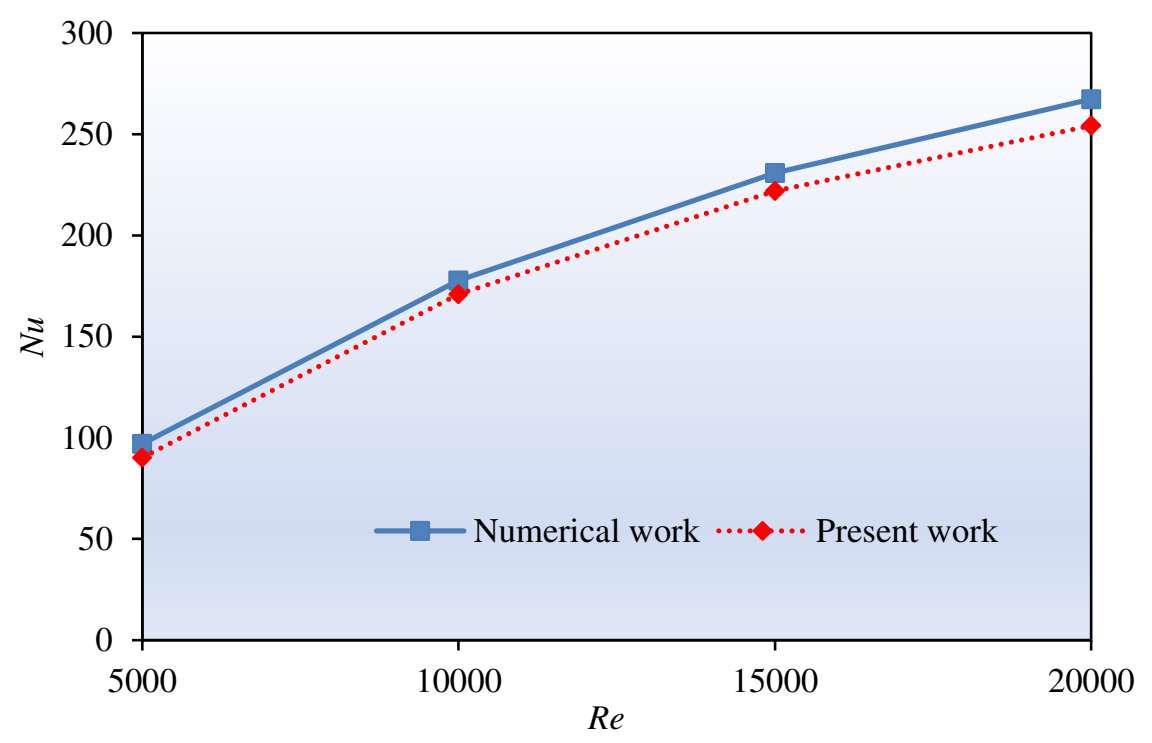

Fig. 3. Validation with numerical work [39].

\section{5. Results and Discussion}

188 The main focus of this numerical investigation is to analyze the turbulent flow of water-CuO NF

189 inside a hairpin heat exchanger with helical baffle in the annulus side. The effects of $\varphi(0-4 \%)$,

$190 \operatorname{Re}(5000-10000)$ and baffle pitch $(25-100 \mathrm{~mm})$ on the performance metrics are investigated.

191 Fig. 4 depicts the contour plots of NF velocity and temperature for different helical baffle pitches

192 at $R e_{n f}=5000$ and $\varphi=4 \%$. It is seen that as baffle pitch augments, the NF velocity 193 diminishes. 

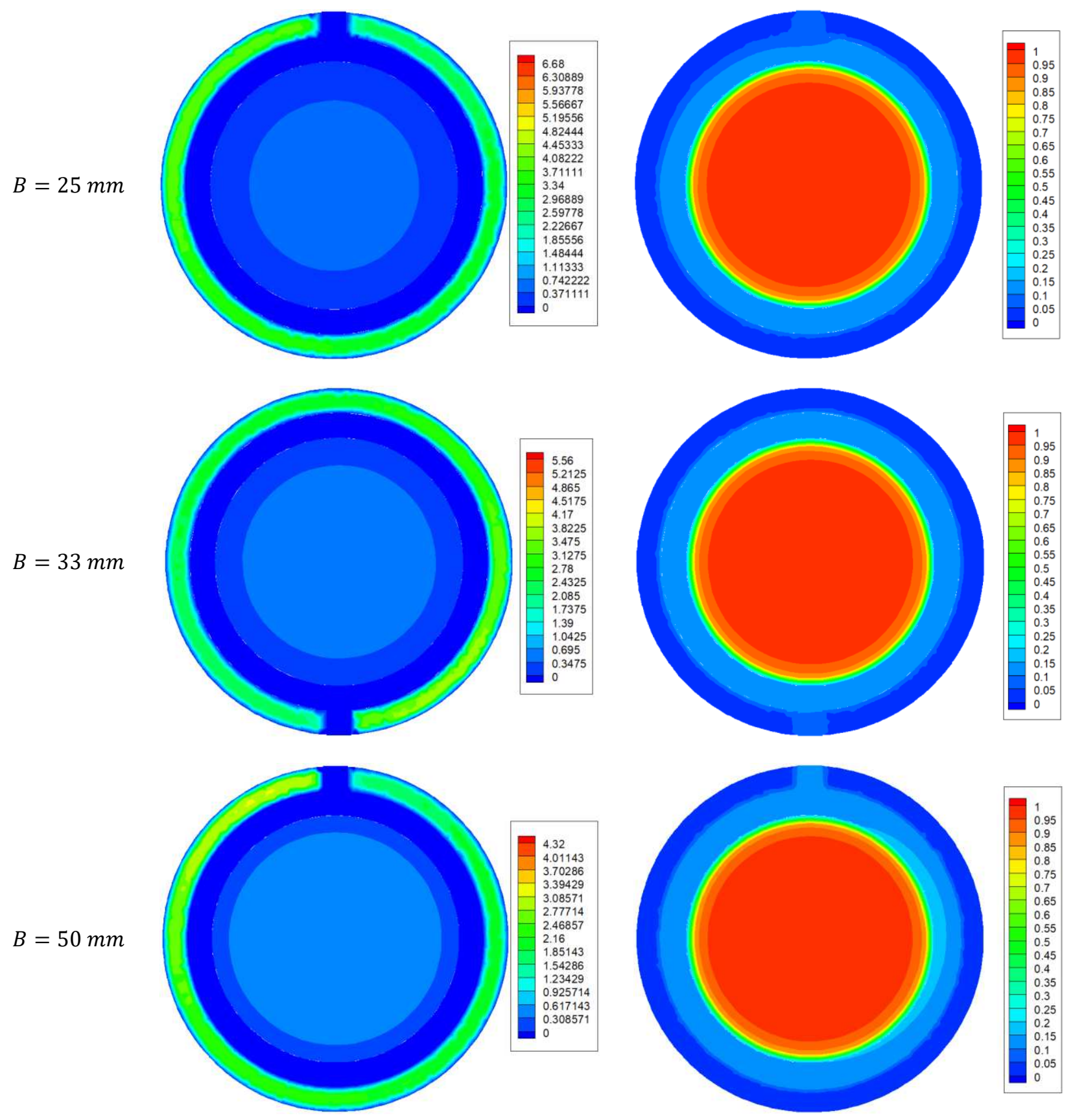

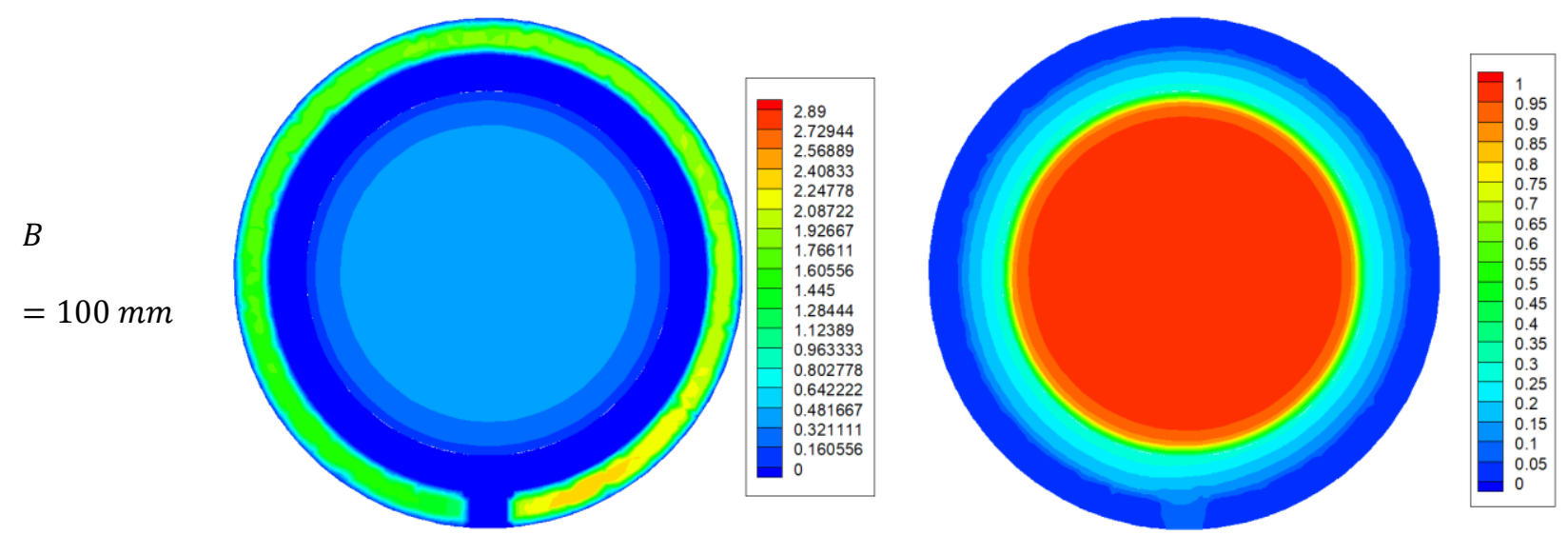

Fig. 4. Contours of NF velocity (left) and temperature (right) in terms of baffle pitch at $R e_{n f}=5000$ and $\varphi=4 \%$.

Fig. 5 gives the consequences of elevating $R e$ on the velocity and temperature contours of NF for

197 baffle pitch of $25 \mathrm{~mm}$. As is seen, intensifying the $R e$ entails an elevation in the NF velocity and 198 a decrement in the NF temperature.
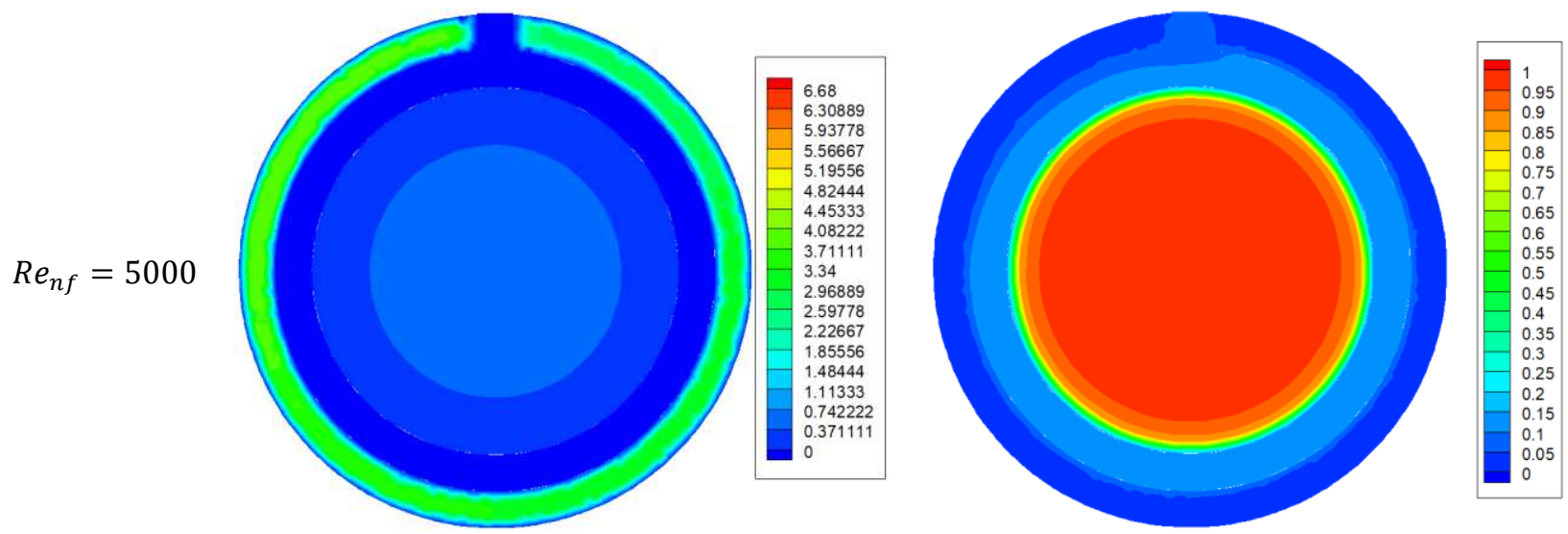


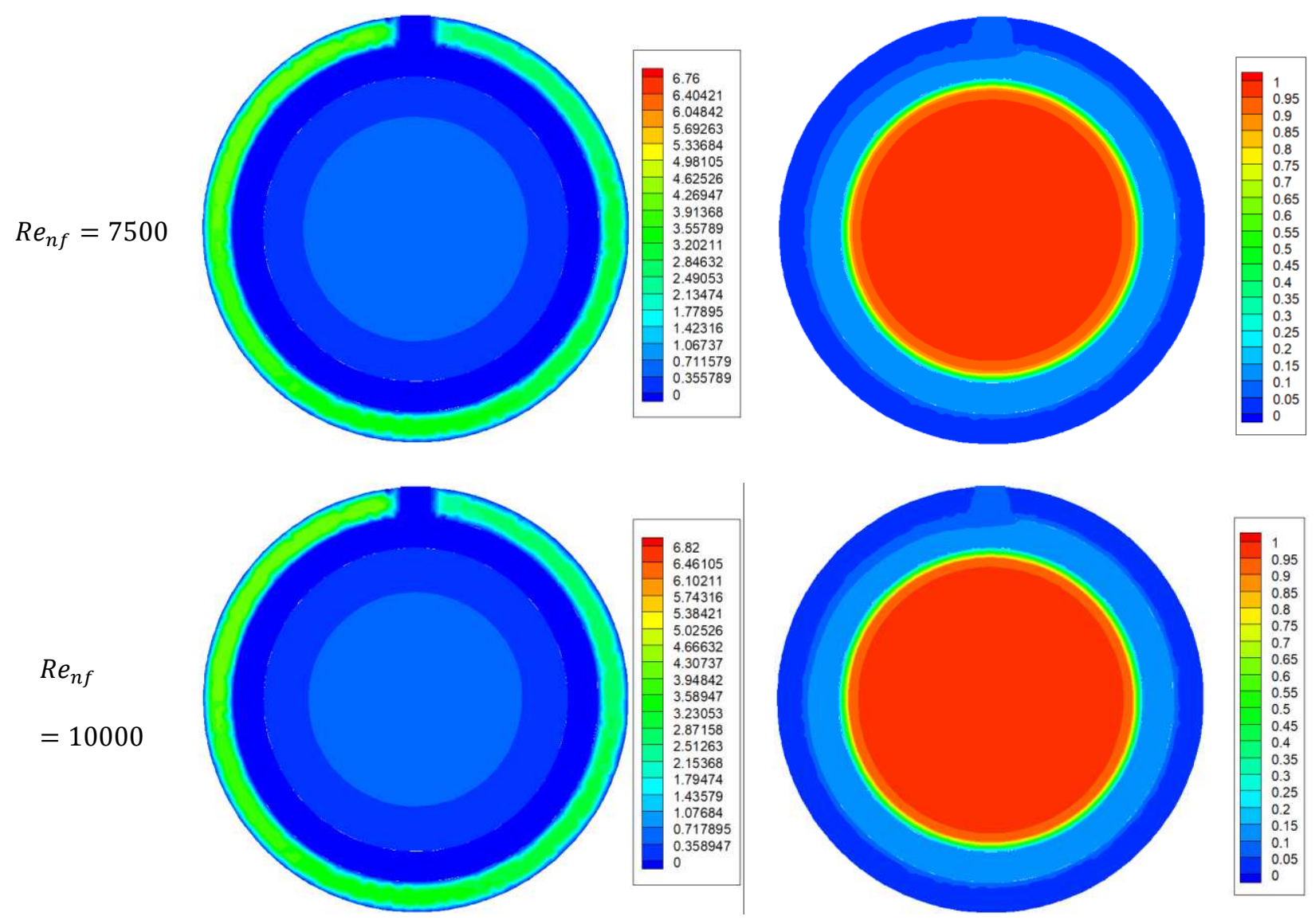

Fig. 5. Contours of NF velocity (left) and temperature (right) in terms of $R e$ for $B=25 \mathrm{~mm}$.

201 Fig. 6 gives the Nusselt number in terms of baffle pitch for various $\varphi$. The Nusselt number 202 improves by elevating both the $\operatorname{Re}$ and $\varphi$, while it declines by augmenting the baffle pitch. For 203 instance, at $R e_{n f}=5000$ and $\varphi=0 \%$, elevating the baffle pitch from 25 to $100 \mathrm{~mm}$ results in a $20419.05 \%$ decrease in the Nusselt number of NF, while this amount for $\varphi=4 \%$ is $15.62 \%$. In 205 addition, at baffle pitch of $25 \mathrm{~mm}$ and $\varphi=4 \%$, intensification of $R e$ from 5000 to 10000 causes 206 a $61.83 \%$ decline in the Nusselt number of NF. Elevating the $R e$ entails a rise in the thickness of 207 the velocity and thermal boundary layer, which elevates the temperature gradient and, 208 consequently, elevates the convective heat transfer coefficient and Nusselt number. Moreover, 209 intensification of $\varphi$ causes an augmentation in the $k_{n f}$ and, thereby, an augmentation in the 
210 convective heat transfer and Nusselt number. Furthermore, intensifying the baffle pitch entail a 211 decrease in the NF velocity and, therefore, a decrease in the convective heat transfer coefficient 212 and Nusselt number.

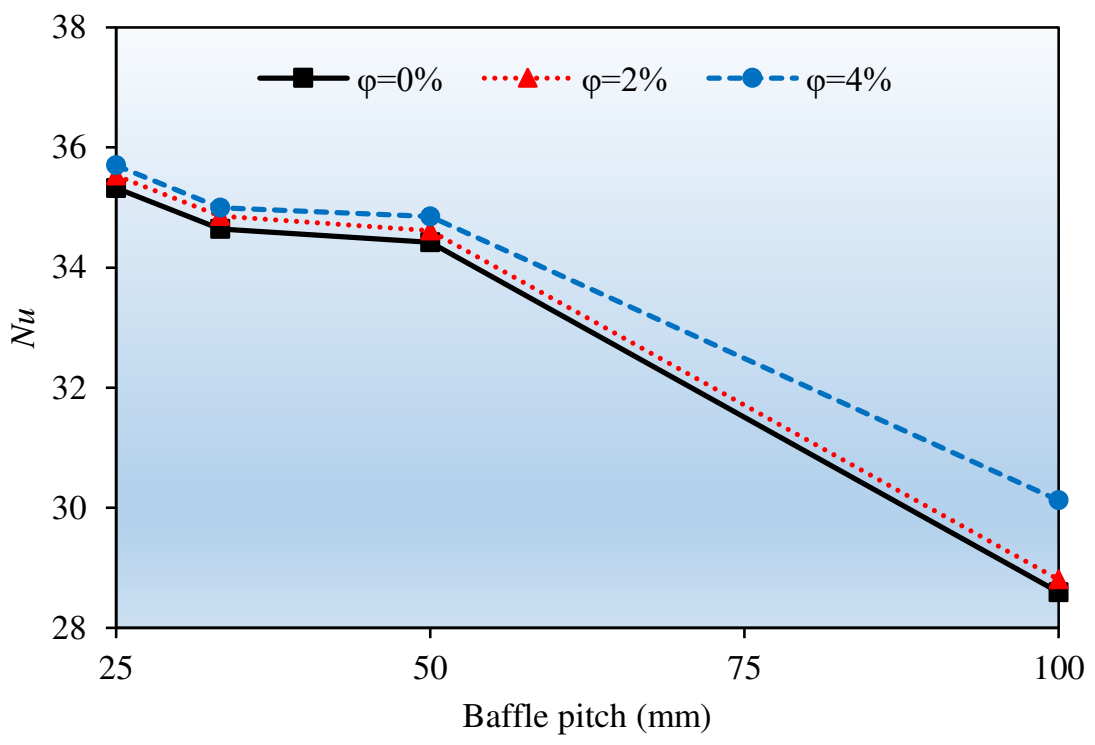

(a)

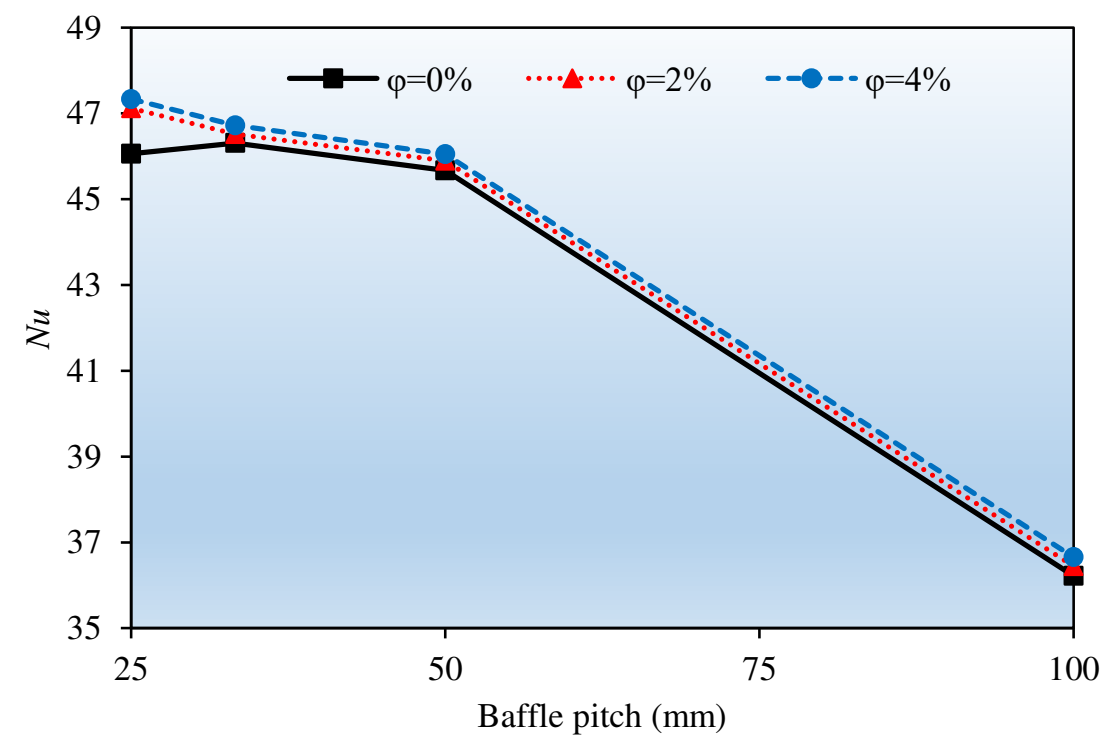

(b) 


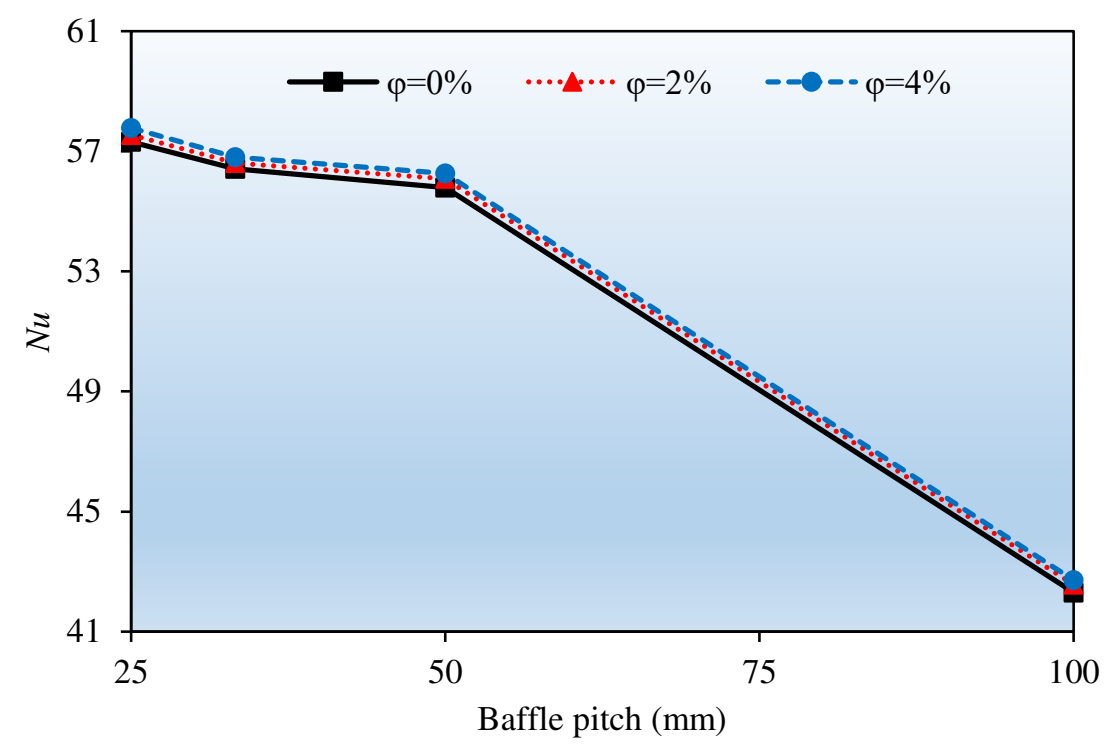

(c)

Fig. 6. Variations of Nusselt number versus baffle pitch in terms of $\varphi$ for (a) $R e_{n f}=5000$, (a) $R e_{n f}=7500$ and (a) $R e_{n f}=10000$.

214 One of the important issues when choosing a working fluid is that the fluid performance should 215 be examined from both the heat transfer and pressure drop (pumping power) aspects. Fig. 7 gives 216 the variations of the pressure drop of NF versus $\varphi$ and baffle pitch for different $R e$. It is observed 217 that the pressure drop intensifies by boosting both the $\varphi$ and $R e$, while it reduces by boosting the 218 baffle pitch. For example, at $R e_{n f}=5000$ and $\varphi=0 \%$, boosting the baffle pitch from 25 to $219100 \mathrm{~mm}$ results in a $73.59 \%$ reduction in the pressure drop of NF, while this amount for $\varphi=4 \%$ 220 is $73.55 \%$. Additionally, at baffle pitch of $25 \mathrm{~mm}$ and $\varphi=4 \%$, augmentation of $\operatorname{Re}$ from 5000 221 to 10000 results in a $232.82 \%$ decrease in the pressure drop of NF. Boosting both the $\operatorname{Re}$ and $\varphi$ 222 causes an elevation in the NF velocity and, therefore, according to Eq. (), the pressure drop of 223 NF elevates. On the other hand, elevating the baffle pitch causes an increment in the annulus 224 fluid path and, as a result, an elevation in the pressure drop, while the NF velocity declines by 
225 boosting the baffle pitch which results in a decrease in the pressure drop of NF. According to the 226 obtained results, it can be concluded the effect of elevated annulus flow path on the pressure 227 drop outweighs the effect of decreases NF velocity and, therefore, the NF pressure drop reduces 228 with an elevation in the baffle pitch.

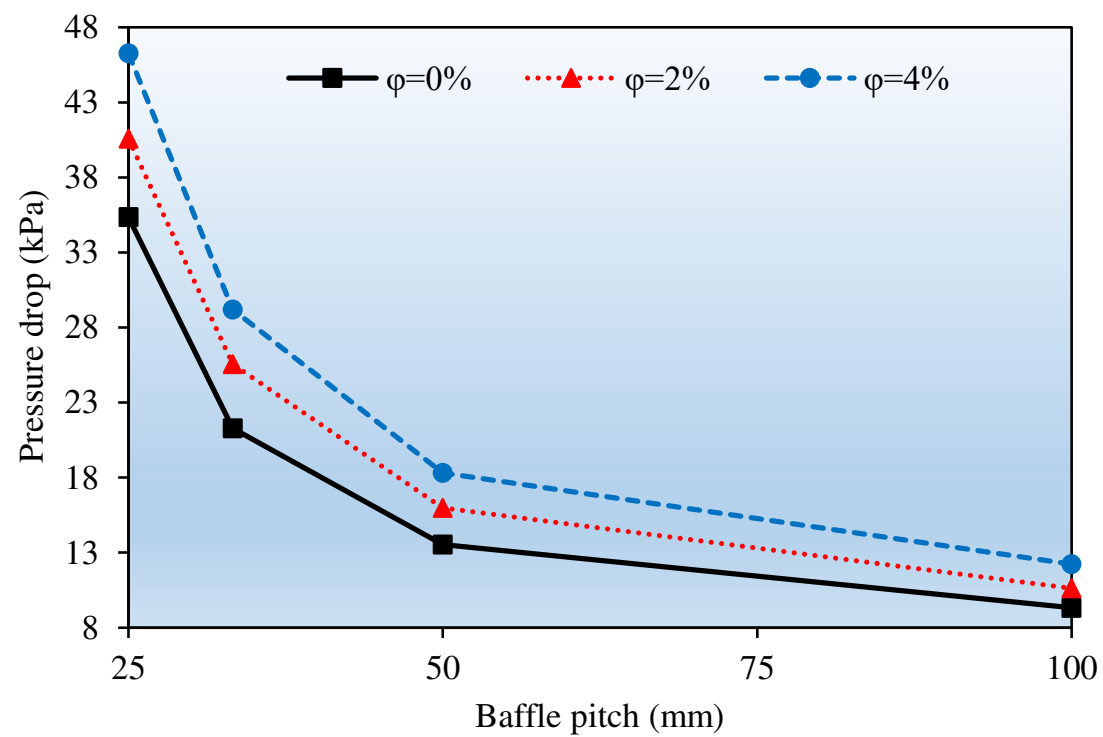

(a)

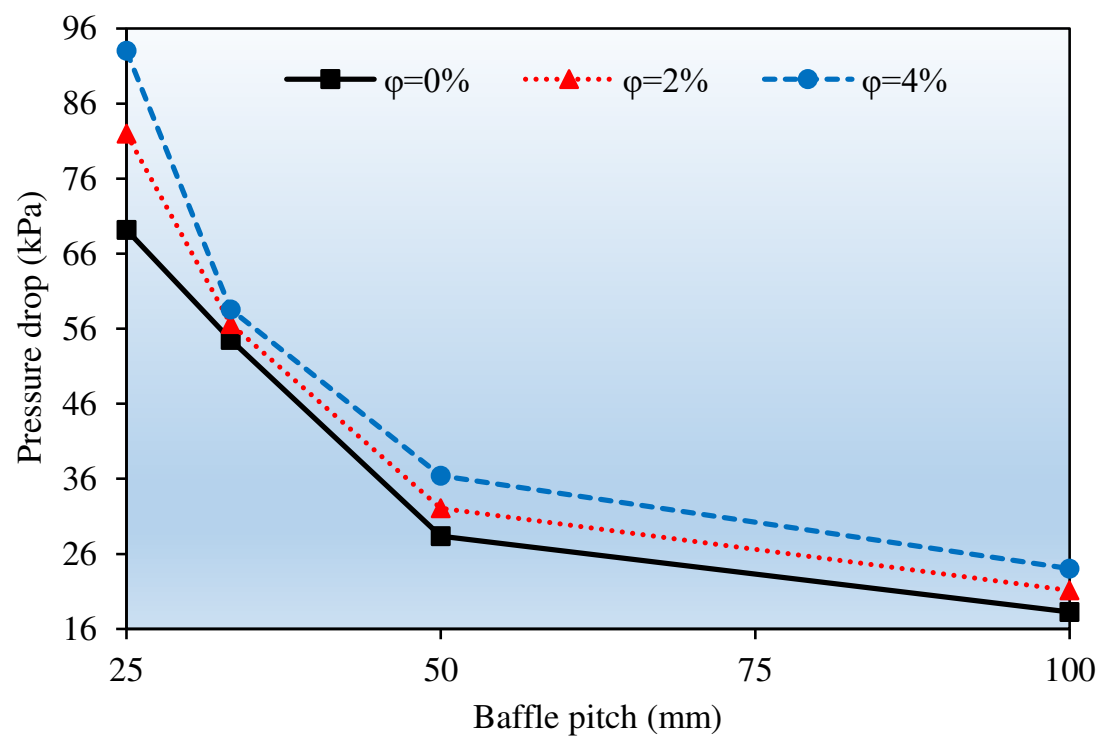


(b)

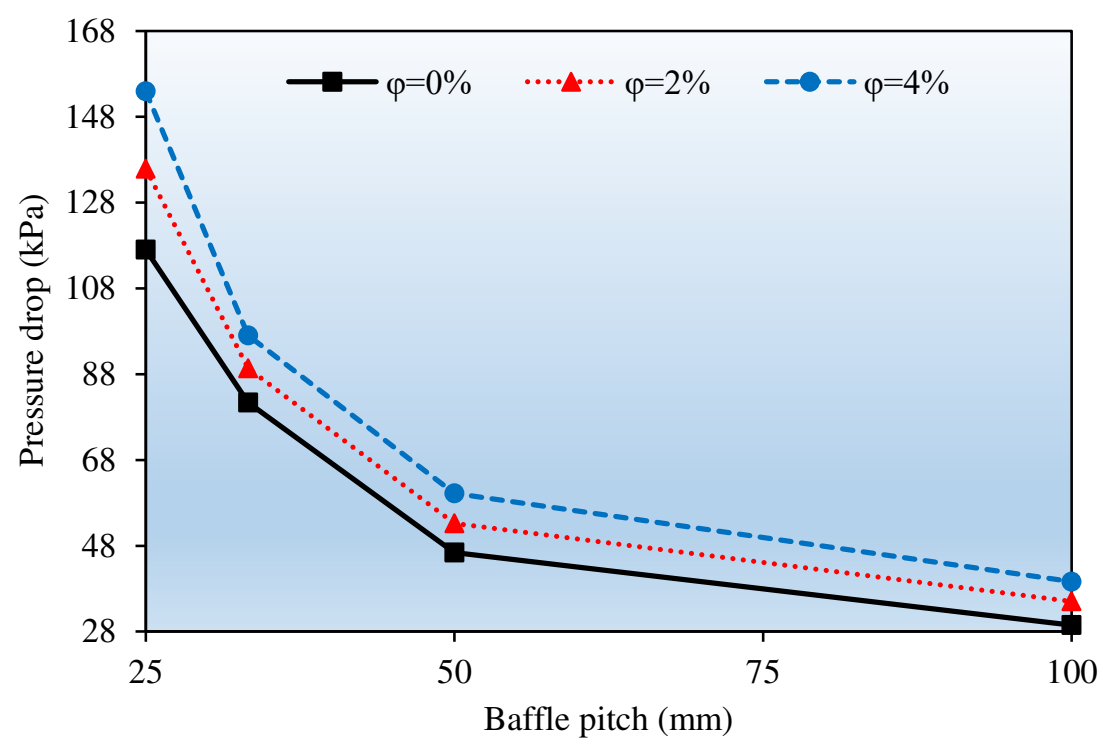

(c)

Fig. 7. Variations of pressure drop versus baffle pitch in terms of $\varphi$ for (a) $R e_{n f}=5000$, (a) $R e_{n f}=7500$ and (a) $R e_{n f}=10000$.

231 The results presented so far have shown that intensifying the $\varphi$ entails an elevated Nusselt 232 number and pressure drop, which the first is a favorable effect and the latter is undesirable. For 233 the final decision on the usefulness of using NF in the heat exchanger under investigation, the 234 performance index should be examined. Fig. 8 demonstrates the variations of the performance 235 index versus $\varphi$ and baffle pitch for different $R e$. The outcomes reveal that the hydrodynamic 236 performance of the water-CuO NF in the considered heat exchanger is superior to that of the pure 237 water in just the following four cases:

- $\quad B=100 \mathrm{~mm}, \varphi=4 \%$ and $R e_{n f}=5000$ where $\eta=1.029$.

- $\quad B=33.3 \mathrm{~mm}, \varphi=2 \%$ and $R e_{n f}=10000$ where $\eta=1.067$

- $\quad B=33.3 \mathrm{~mm}, \varphi=4 \%$ and $R e_{n f}=10000$ where $\eta=1.054$. 
- $B=100 \mathrm{~mm}, \varphi=2 \%$ and $R e_{n f}=10000$ where $\eta=1.000$.

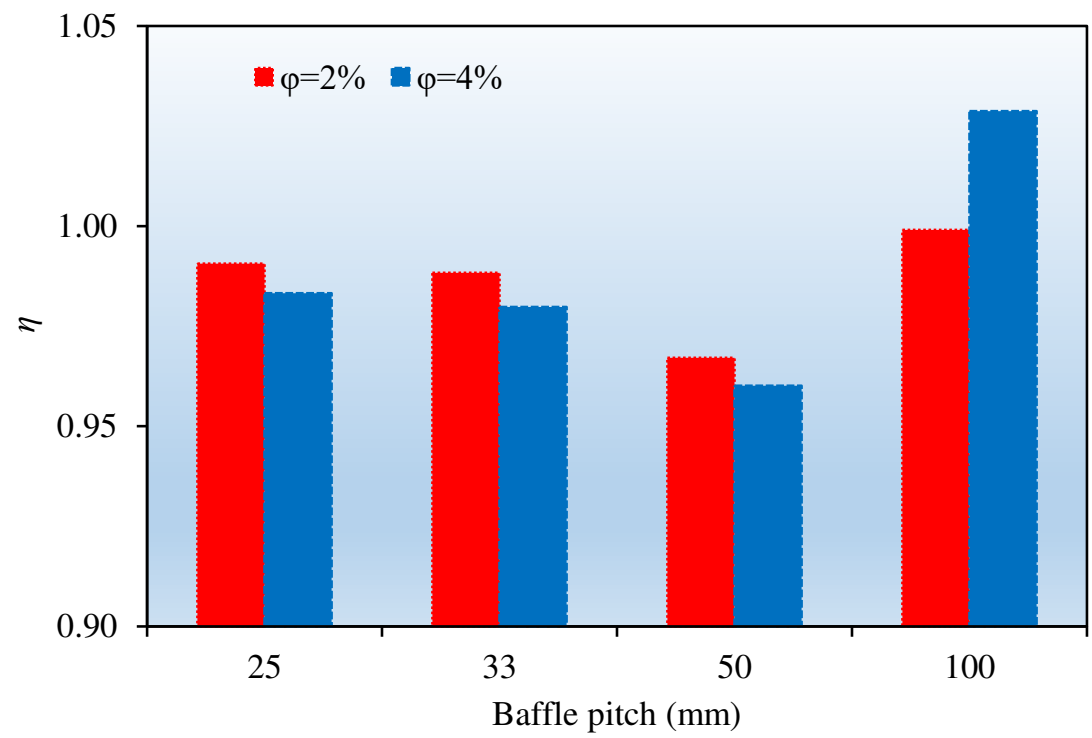

(a)

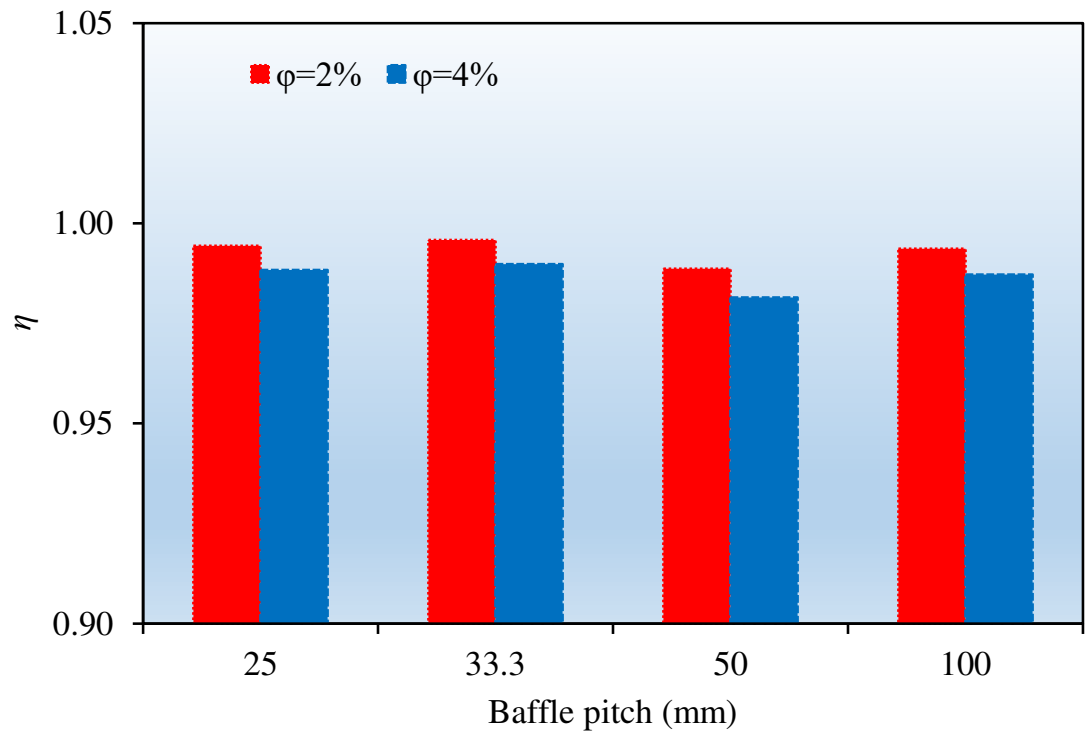

(b) 


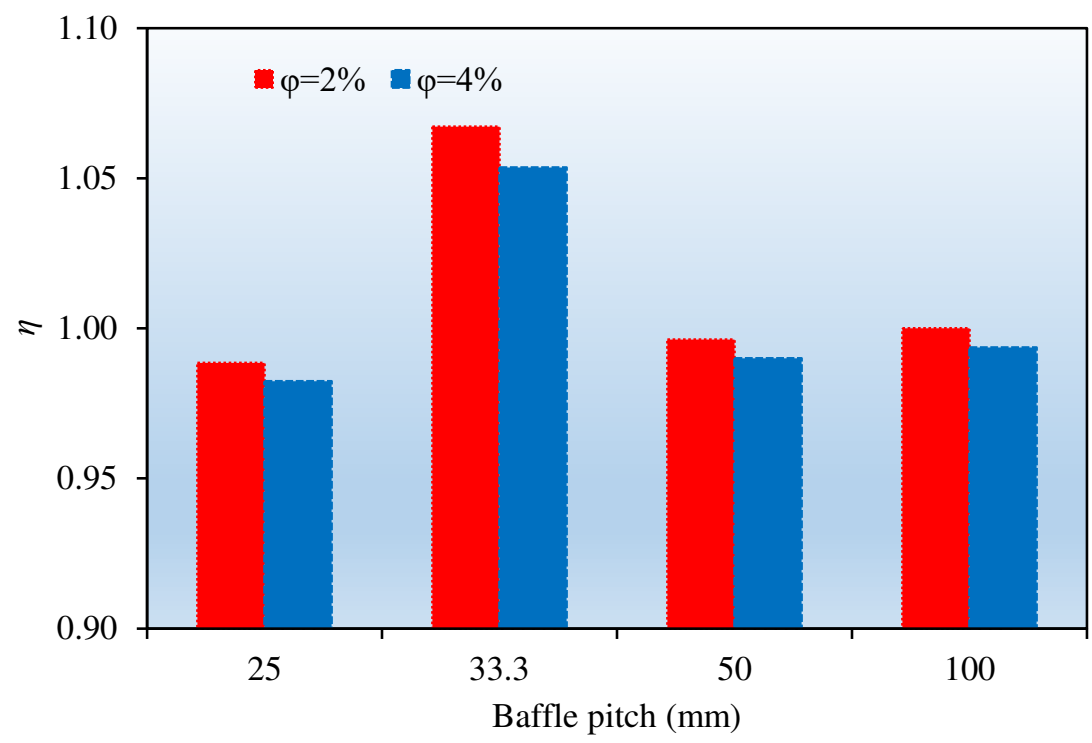

(c)

Fig. 8. Variations of performance index versus baffle pitch in terms of $\varphi$ for (a) $R e_{n f}=5000$, (a) $R e_{n f}=7500$ and (a) $R e_{n f}=10000$.

244 In the remainder of this section, the flow of water-CuO NF with $\varphi=2 \%$ in the considered heat 245 exchanger is examined from the perspective of irreversibility production. Fig. 9 displays the 246 influences of $R e$ and baffle pitch on the frictional irreversibility of NF. As can be seen, the 247 frictional irreversibility declines and rises with increasing baffle pitch and $R e$, respectively, and 248 the $R e$ effect on the frictional irreversibility at lower baffle pitch is greater. For example, at $R e=$ 2495000 , increasing the baffle pitch from 25 to $100 \mathrm{~mm}$ results in a $67.84 \%$ decrease in the 250 frictional irreversibility. In addition, at $B=100 \mathrm{~mm}$, the augmentation of $R e$ from 5000 to 25110000 causes a $209.45 \%$ increment in the frictional irreversibility. By boosting the $R e$ at a 252 constant $\varphi$ (i.e. constant Prandtl number) and baffle pitch, the thickness of the velocity boundary 253 layer decreases, which results in an elevated velocity gradient and thus an elevated frictional 254 irreversibility. On the other hand, increasing the $R e$ at a constant $\varphi$ and baffle pitch, results in an 
255 elevated NF velocity and hence a decrease in the average NF temperature which results in an 256 elevated frictional irreversibility. Elevating the baffle pitch results in a decrease in the flow 257 mixing, which results in a decrease in the velocity gradient and a decrease in the NF temperature, 258 which in turn decreases and elevates the frictional irreversibility. It can be concluded that the 259 decreasing effect of velocity gradient on the frictional irreversibility is overcome by the 260 increasing effect of NF temperature and, therefore, the frictional irreversibility decreases with 261 increasing baffle pitch.

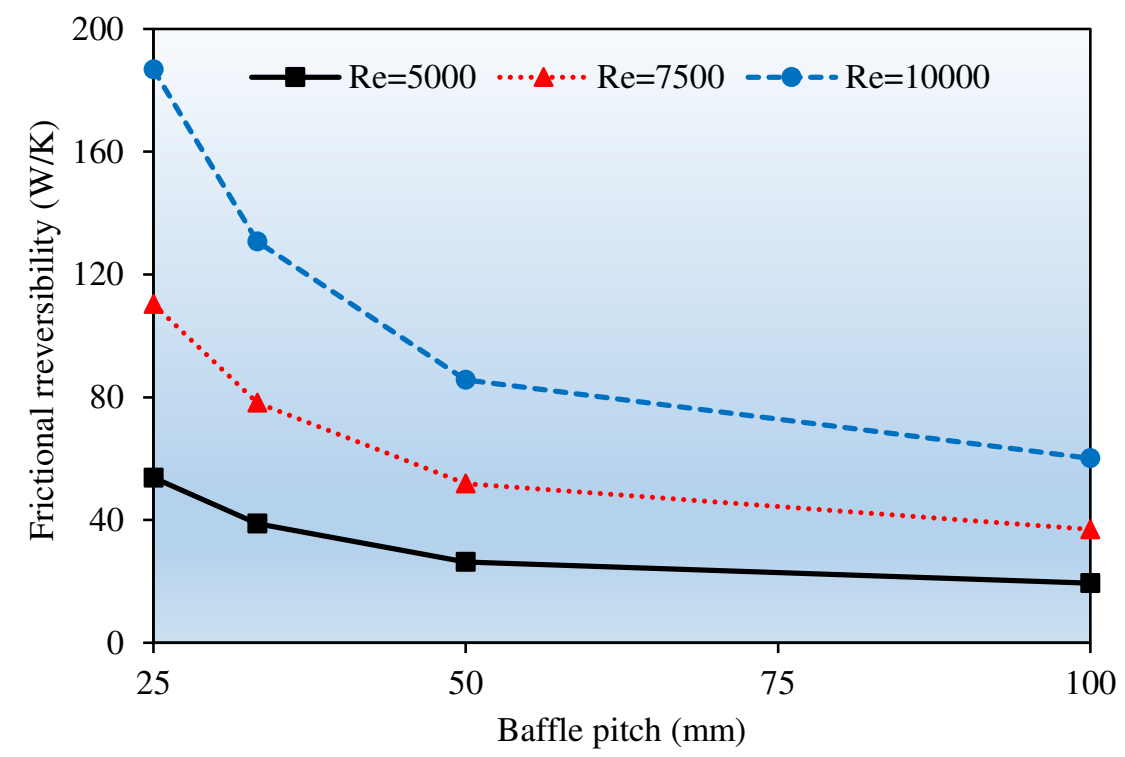

Fig. 9. Variations of frictional irreversibility of NF with $\varphi=2 \%$ versus baffle pitch in terms of $R e$.

264 Fig. 10 givers the changes of thermal irreversibility of NF with $\varphi=2 \%$ versus baffle pitch in 265 terms of $R e$. It is seen that the thermal irreversibility declines with the elevation of $R e$. For 266 example, at $B=100 \mathrm{~mm}$, the intensification of $R e$ from 5000 to 10000 causes a $52.57 \%$ 267 decrease in the thermal irreversibility. As mentioned before, the NF temperature decreases with 268 increasing $R e$ at a constant $\varphi$ and baffle pitch, which results in an elevated thermal 
269 irreversibility. Also, the augmentation of $R e$ results in improved mixing of the flow and 270 consequently, a decrease in the temperature gradient which ultimately results in a decrease in the

271 thermal irreversibility. It can be said that the impact of temperature gradient on the thermal 272 irreversibility outweighs the impact of NF temperature and therefore, the thermal irreversibility

273 declines with the rise of $R e$. Moreover, Fig. 10 shows that with the rise of baffle pitch at a 274 constant $\operatorname{Re}$ and $\varphi$, the thermal irreversibility first elevates and then reduces. The highest thermal 275 irreversibility occurs at baffle pitch of $50 \mathrm{~mm}$. Boosting of baffle pitch at a constant $\varphi$ and $R e$ 276 reduces the flow mixing which results in the decrease of both the NF temperature and 277 temperature gradient which respectively elevates and diminishes the rate of thermal 278 irreversibility. Fig. 10 reveals that for the baffle pitch lower than $50 \mathrm{~mm}$, the increasing impact 279 of temperature outweighs the decreasing of temperature gradient and ultimately, the thermal 280 irreversibility declines while the opposite is true for the baffle pitch higher than $50 \mathrm{~mm}$.

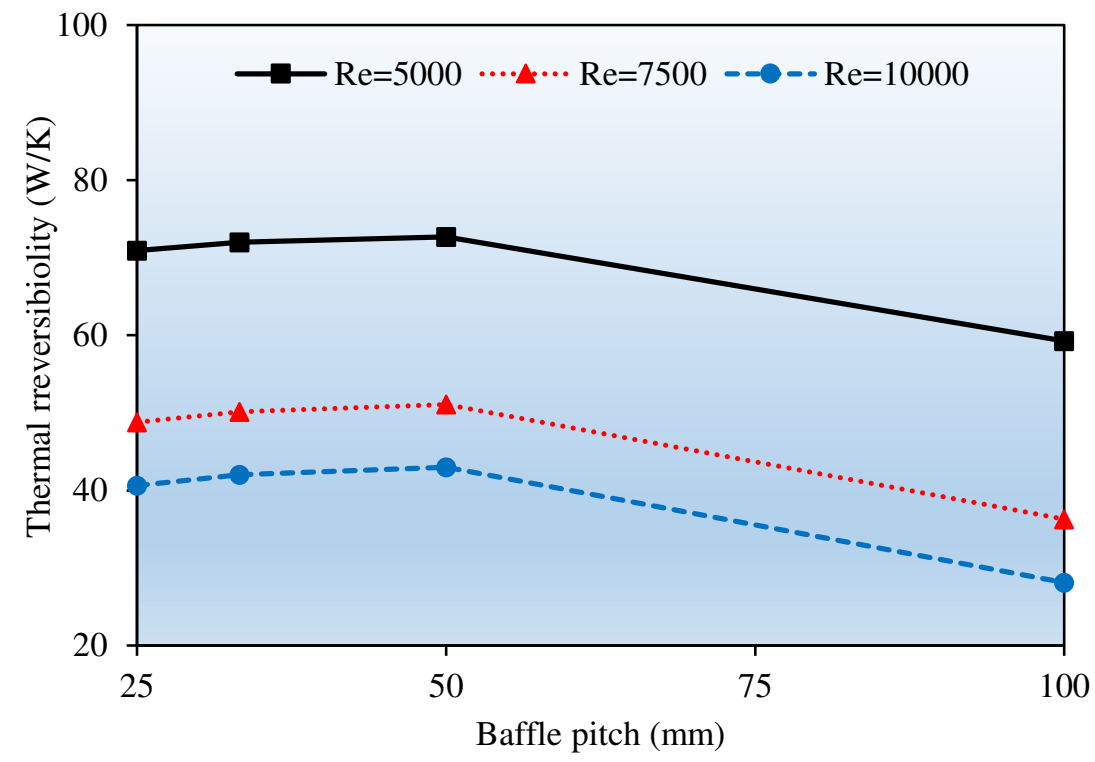

Fig. 10. Variations of thermal irreversibility of NF with $\varphi=2 \%$ versus baffle pitch in terms of $R e$. 
283 The results presented in Figs. 9 and 10 show that increasing the baffle pitch results in a decrease 284 in both the thermal and frictional irreversibilities, and therefore, it can be easily deduced that 285 increasing the baffle pitch entails a declined total irreversibility. However, the influence of $R e$ on 286 the total irreversibility cannot be predicted because the thermal irreversibility elevates with 287 decreasing $R e$ and then decreases. Fig. 11 displays the variations of total irreversibility versus 288 baffle pitch in terms of $R e$. For the baffle pitch of lower than $50 \mathrm{~mm}$, the rise of $R e$ entails an 289 elevated total irreversibility whereas for the baffle pitch of $100 \mathrm{~mm}$, the total irreversibility first 290 elevates with the rise of $R e$ and then decreases. The lowest total irreversibility occurs at $R e=$ 2917500 and $B=100 \mathrm{~mm}$.

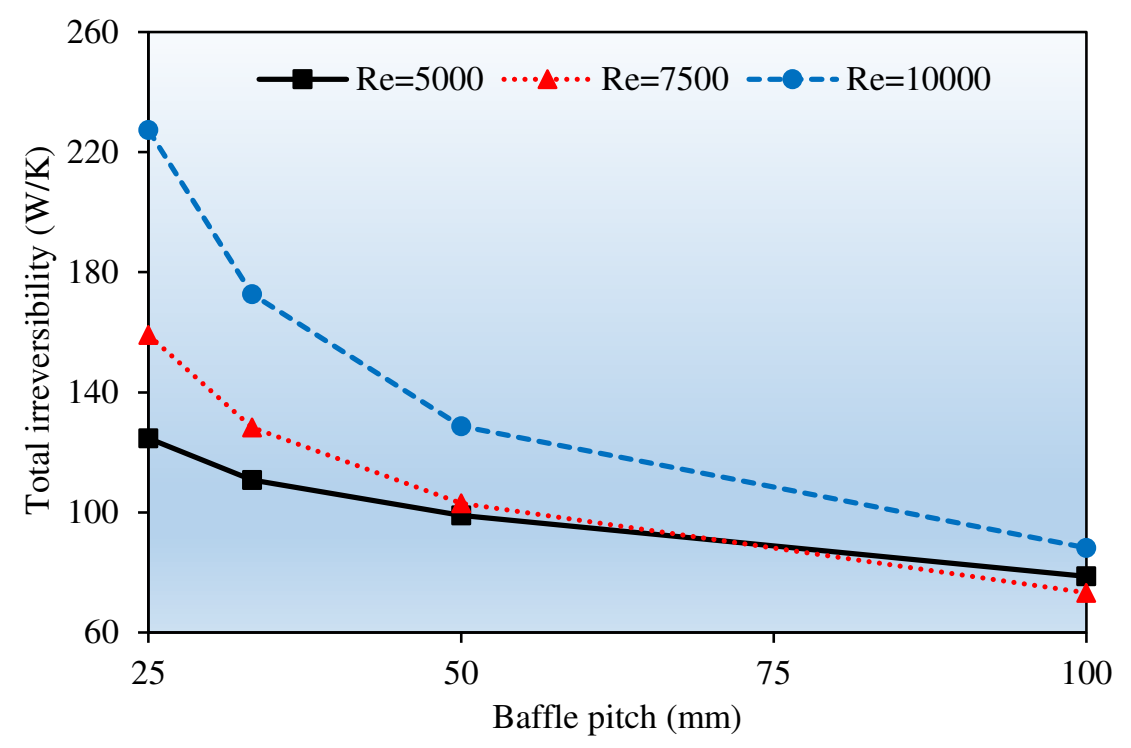

Fig. 11. Variations of thermal irreversibility of NF with $\varphi=2 \%$ versus baffle pitch in terms of $R e$.

293 At the end of this section, we examine how each of the frictional and thermal entropies 294 contribute to the total irreversibility. To investigate this problem, the variations of the Bejan 295 number with the baffle pitch and $R e$ are assessed. As can be seen in Fig. 12, the Bejan number of 296 NF augments with the grow of baffle pitch and decline of $R e$. It is therefore concluded that the 
297 contribution of thermal irreversibility to total irreversibility is higher in lower $R e$ and higher 298 baffle pitch.

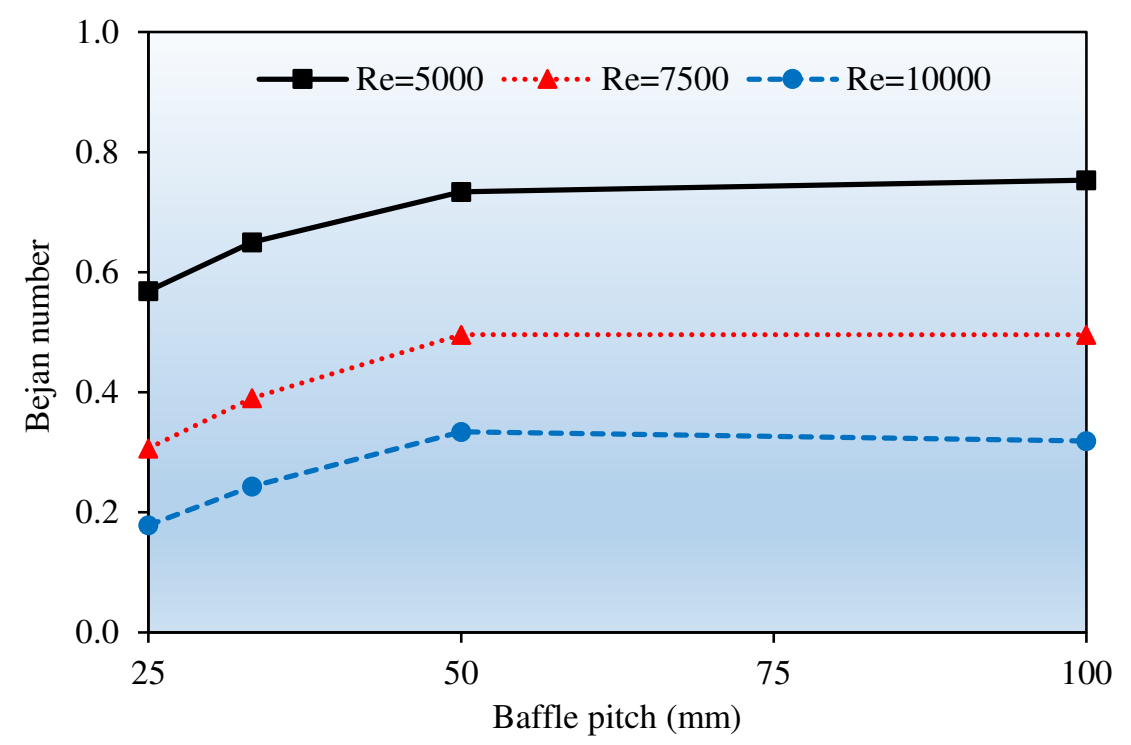

Fig. 12. Variations of Bejan number of NF with $\varphi=2 \%$ versus baffle pitch in terms of $R e$.

300

\section{Conclusion}

302 In this study, the first-law and the-second law of thermodynamics are employed to investigate 303 the turbulent flow of aqueous $\mathrm{CuO} \mathrm{NF}$ through a hairpin heat exchanger equipped with helical 304 baffle in the annulus side. The influence of $\operatorname{Re}(5000-10000), \varphi(0-4 \%)$ and baffle pitch (25-100 $305 \mathrm{~mm}$ ) on the performance metrics are assessed. The following results can be deduced from this 306 simulation:

307 - With the rise of baffle pitch at a constant $R e$ and $\varphi$, the thermal irreversibility first 308 elevates and then reduces.

309 - Intensifying the $R e$ entails an elevated NF velocity and a declined NF temperature. 
- Pressure drop intensifies by boosting both the $\varphi$ and $R e$, while it reduces by boosting the baffle pitch.

- Frictional irreversibility declines and rises with increasing baffle pitch and $R e$, respectively.

- $\quad R e$ effect on the frictional irreversibility at lower baffle pitch is greater.

\section{References}

[1] M.S. Nazir, A. Shahsavar, M. Afrand, M. Arici, S, Nizetic, Z. Ma, H.F. Oztop, A comprehensive review of parabolic trough solar collectors equipped with turbulators and numerical evaluation of hydrothermal performance of a novel model, Sustainable Energy Technologies and Assessments 45 (2021) 101103.

[2] S. Rostami, A. Shahsavar, G.R. Kefayati, A. Shahsavar Goldanlou, Energy and exergy analysis of using turbulator in a parabolic trough solar collector filled with mesoporous silica modified with copper nanoparticles hybrid nanofluid, Energies 13 (2020) 2946.

[3] M.B. Elsheniti, M.O. Elbessomy, K. Wagdy, O.A. Elsamni, M.M. Elewa, Augmenting the distillate water flux of sweeping gas membrane distillation using turbulators: A numerical investigation, Case Studies in Thermal Engineering 26 (2021) 101180.

[4] Q. Xiong, M. Izadi, M. Shokri rad, S.A. Shehzad, H.A. Mohammed, 3D Numerical Study of Conical and Fusiform Turbulators for Heat Transfer Improvement in a Double-Pipe Heat Exchanger, International Journal of Heat and Mass Transfer 170 (2021) 120995.

[5] M.E. Nakhchi, M. Hatami, M. Rahmati, Effects of $\mathrm{CuO}$ nano powder on performance improvement and entropy production of double-pipe heat exchanger with innovative perforated turbulators, Advanced Powder Technology 32 (2021) 3063-3074. 
333 [6] Y. Khetib, H. Sait, B. Habeebullah, A. Hussain, Numerical study of the effect of curved 334 turbulators on the exergy efficiency of solar collector containing two-phase hybrid nanofluid, 335 Sustainable Energy Technologies and Assessments 47 (2021) 101436.

336 [7] I. Bashtani, J.A. Esfahani, K.C. Kim, Effects of water-aluminum oxide nanofluid on double 337 pipe heat exchanger with gear disc turbulators: A numerical investigation, Journal of Taiwan 338 Institute of Chemical Engineers 124 (2021) 63-74.

339 [8] H.A. Mohammed, H.B. Vuthaluru, S. Liu, Heat transfer augmentation of parabolic trough 340 solar collector receiver's tube using hybrid nanofluids and conical turbulators, Journal of Taiwan 341 Institute of Chemical Engineers 125 (2021) 215-242.

342 [9] M. Jafaryar, M. Sheikholeslami, R. Moradi, Nanofluid turbulent flow in a pipe under the 343 effect of twisted tape with alternate axis, Journal of Thermal Analysis and Calorimetry 135 344 (2019) 305-323.

345 [10] M. Khoshbaght-Aliabadi, M. Farsi, S.M. Hassani, N.H. Abu-Hamdeh, A. Alimoradi, 346 Surface modification of transversely twisted-turbulator using perforations and winglets: An 347 extended study, International Communications in Heat and Mass Transfer 120 (2021) 105020.

348 [11] S.U.S. Choi, Enhancing thermal conductivity of fluids with nanoparticles, ASME FED 231 349 (1995) 99-105.

350 [12] A.H. Pordanjani, S. Aghakhani, M. Afrand, B. Mahmoudi, O. Mahian, S. Wongwises, An 351 updated review on application of nanofluids in heat exchangers for saving energy, Energy 352 Conversion and Management 198 (2019) 111886.

353 [13] A. Shahsavar, M. Jamei, M. Karbasi, Experimental evaluation and development of 354 predictive models for rheological behavior of aqueous $\mathrm{Fe} 3 \mathrm{O} 4$ ferrofluid in the presence of an 
355 external magnetic field by introducing a novel grid optimization based-Kernel ridge regression 356 supported by sensitivity analysis, Powder Technology 393 (2021) 1-11.

357 [14] A. Shahsavar, M. Shahmohammadi, E.B. Askari, CFD simulation of the impact of tip 358 clearance on the hydrothermal performance and entropy generation of a water-cooled pin-fin 359 heat sink, International Communications in Heat and Mass Transfer 126 (2021) 105400.

360 [15] A. Shahsavar, M. Rashidi. C. Yildiz, M. Arici, Natural convection and entropy generation of 361 Ag-water nanofluid in a finned horizontal annulus: A particular focus on the impact of fin 362 numbers, International Communications in Heat and Mass Transfer 125 (2021) 105349.

363 [16] E. Bellos, C. Tzivanidis, D. Tsimpoukis, Enhancing the performance of parabolic trough 364 collectors using nanofluids and turbulators, Renewable and Sustainable Energy Reviews 91 365 (2018) 358-375.

366 [17] M.E. Nakhchi, J.A. Esfahani, Numerical investigation of turbulent Cu-water nanofluid in 367 heat exchanger tube equipped with perforated conical rings, Advanced Powder Technology 30 368 (2019) 1338-1347.

369 [18] E.F. Akyurek, K. Gelis, B. Sahin, E. Manay, Experimental analysis for heat transfer of 370 nanofluid with wire coil turbulators in a concentric tube heat exchanger, Results in Physics 9 371 (2018) 376-389.

372 [19] Q. Xiong, M. Jafaryar, A. Divsalar, M. Sheikholeslami, A. Shafee, D.D. Vo, M.H. Khan, I. 373 Tlili, Z. Li, Macroscopic simulation of nanofluid turbulent flow due to compound turbulator in a 374 pipe, Chemical Physics 527 (2019) 110475.

375 [20] Q. Xiong, M. Ayani, A.A. Barzinjy, R.N. Dara, A. Shafee, T. Nguyen-Thoi, Modeling of 376 heat transfer augmentation due to complex-shaped turbulator using nanofluid, Physica A 540 $377 \quad$ (2020) 122465. 
378 [21] H.E. Ahmed, M.Z. Yusoff, M.N.A. Hawlader, M.I. Ahmed, B.H. Salman, A.Sh. Kerbeet, 379 Turbulent heat transfer and nanofluid flow in a triangular duct with vortex generators, 380 International Journal of Heat and Mass Transfer 105 (2017) 495-504.

381 [22] M. Sheikholeslami, M. Jafaryar, J.A. Ali, S.M. Hamad, A. Divsalar, A. Shafee, T. Nguyen-

382 Thoi, Z. Li, Simulation of turbulent flow of nanofluid due to existence of new effective 383 turbulator involving entropy generation, Journal of Molecular Liquids 291 (2019) 111283.

384 [23] Z. Li, M. Sheikholeslami, M. Jafaryar, A. Shafee, A.J. Chamkha, Investigation of nanofluid 385 entropy generation in a heat exchanger with helical twisted tapes, Journal of Molecular Liquids $386266(2018) 797-805$.

387 [24] S.A. Farshad, M. Sheikholeslami, Nanofluid flow inside a solar collector utilizing twisted 388 tape considering exergy and entropy analysis, Renewable Energy 141 (2019) 246-258.

389 [25] A.A.A.A. Al-Rashed, R. Ranjbarzadeh, S. Aghakhani, M. Soltanimehr, M. Afrand, T.K. 390 Nguyen, Entropy generation of boehmite alumina nanofluid flow through a minichannel heat 391 exchanger considering nanoparticle shape effect, Physica A 521 (2019) 724-736.

392 [26] P. Barnoon, D. Toghraie, F. Eslami, B. Mehmandoust, Entropy generation analysis of 393 different nanofluid flows in the space between two concentric horizontal pipes in the presence of 394 magnetic field: Single-phase and two-phase approaches, Computers \& Mathematics with 395 Applications 77 (2019) 662-692.

396 [27] P. Barnoon, D. Toghraie, R.B. Dehkordi, H. Abed, MHD mixed convection and entropy 397 generation in a lid-driven cavity with rotating cylinders filled by a nanofluid using two phase 398 mixture model, Journal of Magnetism and Magnetic Materials 483 (2019) 224-24. 
399 [28] Z. Li, P. Barnoon, D. Toghraie, R.B. Dehkordi, M. Afrand, Mixed convection of non400 Newtonian nanofluid in an $\mathrm{H}$-shaped cavity with cooler and heater cylinders filled by a porous 401 material: Two phase approach, Advanced Powder Technology 30 (2019) 2666-2685.

402 [29] P. Barnoon, D. Toghraie, R.B. Dehkordi, M. Afrand, Two phase natural convection and 403 thermal radiation of Non-Newtonian nanofluid in a porous cavity considering inclined cavity and 404 size of inside cylinders, International Communications in Heat and Mass Transfer 108 (2019) 405104285.

406 [30] J.C. Maxwell, Treatise on electricity and magnetism, Oxford: Clarendon Press, 1873.

407 [31] H. Brinkman, The viscosity of concentrated suspensions and solutions, The journal of 408 chemical physics 20 (1952) 571-577.

409 [32] B.C. Pak, Y.L. Cho, Hydrodynamic and heat transfer study of dispersed fluids with 410 submicron metallic oxide particles, Experimental Heat Transfer an International Journal 11 411 (1998) 141-170.

412 [33] Y. Xuan, W. Roetzel, Conceptions for heat transfer correlation of nanofluids, International 413 Journal of Heat and Mass Transfer 43 (2000) 3701-3707.

414 [34] M. Bahiraei, A. Godini, A. Shahsavar, Thermal and hydraulic characteristics of a 415 minichannel heat exchanger operated with a non-Newtonian hybrid nanofluid, Journal of the 416 Taiwan Institute of Chemical Engineers 84 (2018) 149-161.

417 [35] J. Alsarraf, A. Moradikazerouni, A. Shahsavar, M. Afrand, M.D. Tran, Hydrothermal 418 analysis of turbulent boehmite alumina nanofluid flow with different nanoparticle shapes in a 419 minichannel heat exchanger using two-phase mixture model, Physica A 520 (2019) 275-288. 
420 [36] A. Karimi, A.A.A.A. Al-Rashed, M. Afrand, O. Mahian, A. Shahsavar, The effects of tape 421 insert material on the flow and heat transfer in a nanofluid-based double tube heat exchanger:

422 Two-phase mixture model, International Journal of Mechanical Sciences 156 (2019) 397-409.

423 [37] D. Wen, Y. Ding, Experimental investigation into convective heat transfer of nanofluids at 424 the entrance region under laminar flow conditions, International Journal of Heat and Mass 425 Transfer 47 (2004) 5181-5188.

426 [38] S. Göktepe, K. Atalık, H. Ertürk, Comparison of single and two-phase models for nanofluid 427 convection at the entrance uniformly heated tube, International Journal of Thermal Sciences 80 428 (2014) 83-92.

429 [39] S.M. Vanaki, H.A. Mohammed, Numerical study of nanofluid forced convection flow in 430 channels using different shaped transverse ribs, International Communications in Heat and Mass 431 Transfer 67 (2015) 176-188. 